\title{
Barriers to Antenatal Care Use among Pregnant Women
}

\author{
Omar Hussein ${ }^{1}$, Waleed Ghanim Ahmed ${ }^{2}$ \\ ${ }^{1}$ M.Sc. Community Health Nursing, Department of Clinical Nursing Science, College of Nursing, University of \\ Mosul, Iraq, ${ }^{2}$ Assistant Professor, Community Medicine, College of Medicine, University of Mosul, Iraq
}

\begin{abstract}
Background: Antenatal care is the routine health program of pregnant women to reduce the risk of stillbirths and pregnancy complications and give women a positive pregnancy experience.

Objectives: This study aims to assess the utilization ratio of antenatal care services and to identify current barriers to proper utilization of antenatal care services in Mosul city.

Subjects and Methods: A descriptive study was carried out during the period from 26 September, 2019 to $1^{\text {st }}$ April 2020. The study has been conducted among three hospitals in Mosul city namely: Al- khansaa teaching hospital, Al- salam teaching hospital and Al-batool teaching hospital. The target population was pregnant women who attend maternity and child care unit. The study sample consists of 3000 pregnant women. Data collection tool was composed of (2) main parts. The first one was for socio demographic data about the pregnant woman. The second part was for gynecological, obstetric and antenatal care characteristics. It was constructed through use of (2) option- type (yes-no). Content validity was determined by presenting the items to a panel of scientific experts.

Results: Women with greater obstacles (mean=4.5) were found to be less likely than those with less barriers $(\mathrm{N}=60$, mean $=5.6)$ to receive prenatal care. There was a significant difference in prenatal care attendance between pregnant women who had no prior children (nulliparous) and pregnant women who had at least one prior child (multiparous) If $\mathrm{t}=1.2$, then the significance level is 0.05 .
\end{abstract}

Recommendations: The study recommends establishing several antenatal care clinics in different areas of Mosul city to improve medical and nursing staff caring attitude in addition to increasing people's awareness through health education about the importance of conducting antenatal care visits since the beginning of pregnancy.

Key words: Antenatal care, Obstacles, Utilization, Mosul

\section{Introduction}

Antenatal care is the routine medical and nursing care for pregnant women. ${ }^{(1)}$ It is a preventative treatment that allows physicians or midwives to address and prevent possible health issues during pregnancy. ${ }^{(2,3)}$ Prenatal care is critical since $25 \%$ of maternal fatalities occur during pregnancy, with variations across nations due to unsafe abortion, violence, and illness. Preexisting illnesses may worsen during pregnancy, according to studies. In a study of six West. A third of all pregnant women were sick throughout pregnancy, with $3 \%$ requiring hospitalization.
Each woman's health risks differ based on her pre-pregnancy medical status. $(4,5)$

\section{Method}

\section{Design and Sampling}

This research is a survey research design. The independent variables are: barriers to the use of antenatal care, which was categorized into more barriers and few barriers, child birth experience, categorized into no child birth experience and child birth experience, and level of education, categorized into primary, secondary and tertiary education while the dependent variable is actual attendance of 
antenatal care. Convenience sampling method was used, into the study.

\section{Participants and Setting}

A total of 300 participants were drawn from the population of pregnant women attending antenatal care at thePHCs. The demographic characteristics of the participants for this study are as follows: the participants' ages ranged between 20 and 45 years, mean age $(\overline{\mathrm{x}})=29.8$ years and standard deviation of $(\mathrm{SD})=5.9$. On marital status, $(93.9 \%)$ of the participants were married, while $(6.1 \%)$ were single. On the participants' type of family, 96 (89.7\%) were monogamous while (10.3\%) were polygamous. Participants' years of marriage for this study ranged from 1year (6 months to 1yr) to 18years, while the mean is $\overline{\mathrm{x}}=3.9 \mathrm{yrs}$. $(\mathrm{SD}=5.0)$. Their educational status ranged from No school (0.87\%), Primary school $=16$ $(14.0 \%)$, Secondary school (43.0\%) to Tertiary school $(42.1 \%)$.

\section{Measures}

This study utilized a structured questionnaire to gather data. An ethnic group, age, location, educational qualification and marital status are all included in the demographic section. Oyinlola and Sunmola created a new Barriers to Antenatal Care Use Scale (2013) (6). The scale was created and standardized for the research to assess potential obstacles to prenatal care. It has 31 items with Yes/No responses. These obstacles fall into three categories: choice to seek treatment, access to care, and appropriate care. Pregnancy is a private issue and I don't want to speak about it with anybody other than my family members. All things are negative. The scale is assessed by adding up the answers and dividing by 31 , with higher scores indicating more obstacles and lower scores indicating less. Alignment is 0.63. Actual Attendance of Antenatal Care Scale established by Oyinlola and Sunmola (2013) $\left({ }^{6}\right)$. The scale asks three questions: did you keep your previous appointment? Did you keep your last two prenatal appointments? Did you keep all three of your last appointments? The participant's answers were verified by looking up their prenatal appointment cards in the clinic's records. If a pregnant woman misses one prenatal visit in the past three, she is not regularly attending antenatal care appointments. The scale's internal consistency was 0.81 .

\section{Procedure}

From the start, all respondents were fully informed of the study's academic character. Before giving permission, they were assured of their answers' privacy and secrecy. The questionnaire was given in Arabic and all participants completed it independently. Two research assistants helped distribute the surveys. The research utilized a total of 118 questionnaires, of which 118 were well-completed. The finished copies were graded and analyzed using Stata 17.0. The research received ethical clearance from the Mosul Ministry of Health and informed permission from the pregnant women. The data was analyzed using descriptive statistics, t-tests, and one-way ANOVA.

\section{Results}

When pregnant women encounter more obstacles, their attendance at prenatal care decreases ( $p$ 0.05) compared to pregnant women who don't face as many. Thus, women with fewer obstacles (mean $=5.6)$ were more likely to attend prenatal care than those with higher barriers $($ mean $=4.5)$, according to the study. Compared to women with secondary and tertiary degrees, women with just a primary education were less likely to seek prenatal care, $\mathrm{P}>0.05$ ), as shown in Table 2. This shows that the degree of education of the participants had no effect on their actual attendance at prenatal care. Compared to women who have had at least one child, pregnant women with no children are more likely to go to prenatal 
care, as seen in Table $3 \mathrm{p}>0.05$ ). Compared to women who had at least one child, pregnant women who had no children mean $=5.2$ ) were more likely to receive prenatal care.

Table1. "independent t-test comparing pregnant women on levels of barriers and actual attendance".

\begin{tabular}{llcccccc}
\hline Variable & Barriers & N & Mean & SD & t & df & p \\
\hline Actual & Fewer & 120 & 5.2 & 0.9 & & & \\
Attendance & & & & & 8.0 & 298 & 0.05 \\
& More & 80 & 4.3 & 0.7 & & & \\
\hline
\end{tabular}

Table 2. "Analyses of Variance (Anova) showing the influence of education on actual attendance of antenatal care".

\begin{tabular}{lccccc}
\hline Source of Variance & $\begin{array}{c}\text { Sum of } \\
\text { Squares }\end{array}$ & df & $\begin{array}{c}\text { Mean of } \\
\text { Squares }\end{array}$ & $\mathbf{F}$ & $\mathbf{p}$ \\
\hline Between Groups & 5.4 & 3 & 1.8 & & \\
Within Groups & 197.5 & 295 & 0.7 & 2.6 & 0.82 \\
Total & 202.9 & 298 & & & \\
\hline
\end{tabular}

Table 3. "Independent t-test, showing the influence of child birth experience by pregnant women on actual attendance".

\begin{tabular}{llllllll}
\hline Variable & No.ofchildren & N & MeanSD & df & t & p \\
\hline Actual & Nochild & 166 & 4.6 & 1.2 & & & \\
Attendance & & & & & 298 & 0.1 & 0.078 \\
& $\geq 1$ child & 34 & 3.8 & 1.3 & & & \\
& & & & & & & \\
\hline
\end{tabular}

\section{Discussion}

The first hypothesis held. Contrary to popular belief, pregnant women who encounter greater obstacles are less likely to receive prenatal care. For example, Galmararian, Schwartz, Amacker and Powell (2007)( ${ }^{7)}$ found links between low prenatal care initiation and low maternal satisfaction (Strickland and Strickland,1996) ${ }^{(8)}$. Attendance at prenatal care was inconsistent among pregnant women who believed pregnancy is a personal matter that should be kept private. This was discovered to be a cultural problem throughout the study. An evil spirit is said to enter a pregnant woman's womb if she announces her pregnancy. In addition to using herbs, 43.6 percent of pregnant women did not regularly visit prenatal care. According to the study, $25 \%$ of pregnant women who chose traditional delivery attendants did not visit prenatal care often enough. In the Akinyele local government general hospital, pregnant women face significant obstacles that may prevent them from regularly attending antenatal care. They were clearly still devoted to their traditional pregnancy care. Financial and cultural obstacles to prenatal care availability and use have also 
been highlighted by Lincetto et al $(2006)^{(9)}$. While money is a problem for some pregnant women, 3.1 percent did not regularly attend prenatal care due to their belief that it was costly. Hypothesis two was ruled out. Contrast this with pregnant women with secondary or higher education who were more likely to receive prenatal care. Education did not affect pregnant women's attendance at prenatal care. In the past, individuals may have gained knowledge and insight as a consequence of prior experiences. ${ }^{(10 \text {, }}$ 11) Prenatal care is an important part of a woman's pregnancy and the benefits of attending it outweigh the risks. Preparation for delivery, health information, and support for pregnant women, their families, and communities The lady and her family get relevant information, education, and guidance on diet, sleep, smoking cessation, avoiding alcohol and drugs, and parenting skills. It didn't matter whether participants were literate or not since enough awareness had been established for the pregnant lady via all of this information and instruction. Pregnant women are very highly valued in Africa, particularly among the Yoruba people. Taking care of pregnancy is a social duty for elder women to younger women. This explains why a pregnant lady might seek assistance to deliver her kid even on the highway from a midwife. To conceal the pregnant lady during delivery, the ladies surrounding her remove their wraps. Hypothesis 3 was also confirmed. Less than half of women who have never given birth (nulliparous) will receive prenatal care (multiparous). Women with greater pregnancy experience (multiparous women) and women over 35 years old put less emphasis on prenatal care, according to a research by Regenstein et al. (2005) (12). People who have never given birth are likely to be curious and want to learn about caring for themselves and their unborn children. After achieving a need, people move on to the next level in Abram Maslow's hierarchy of wants (Maslow 1943) ${ }^{(13)}$. Women who have already given birth may not perceive the need to repeat the prenatal care procedure. For these pregnant women, family planning may be a motivation to either space their children or avoid having more.

\section{Conclusion}

Obstacles preventing pregnant women from getting prenatal care were shown to be important in this study. Less formal education did not influence antenatal care attendance among pregnant women who are well-informed about prenatal care. Also, younger women attended prenatal care more than older women who had at least one kid.

\section{Recommendation}

Even though it is the same woman bearing the baby, each pregnancy and birth is unique and should be handled as such. So that people they want to help or care for do not see them as evil, this research encourages health care professionals, especially doctors and nurses, to be patient with their patients. Emphasis should be placed on prenatal care and treating each pregnancy as a unique experience. The study's findings lead to these recommendations. Barriers prevent achieving a goal. They want healthy kids with little or no issues. Achieving this goal is important to the community. WHO, UNICEF, and Save the Children are among those concerned about maternal and newborn health. 14-15) While this study recognizes previous efforts to educate and inform pregnant women, the work should not stop there. Encourage pregnant women to seek prenatal care and to treat each pregnancy uniquely. Simply stated, people's attitudes about health problems, perceived benefits, and barriers influence their adherence to healthy habits. Prenatal care benefits should be regularly highlighted, while perceived barriers should be reduced. When pregnant women skip antenatal appointments, doctors and nurses should visit them at home. Vaccination programs for children, for example, need mobile health workers to go door to 
door. Similarly, pregnant women should be vaccinated and given the appropriate medications. It will also help erase negative views of doctors and nurses among pregnant women, since they will be leaving clinics to visit patients at home. Physicians and nurses may also call patients to remind them of appointments and check on their health. Doctors, nurses, and midwives should also be trained in prenatal care. Researchers found that pregnant women's illness behavior differs. Women should avoid herbalists and traditional birth attendants who offer them possibly hazardous medications and combinations.

Ethical Clearance-: The ethical approval was obtained for the Research Ethics Committee at Nineveh Health Directorate, Mosul Region, Iraq, before this study. The purpose was briefly explained to participants, and their consent was obtained. They were informed that they had the full right to withdraw at any time.

\section{Source of Funding- Self}

\section{Conflict of Interest- Nil}

\section{Bibliography}

1. Oakley A. The origins and development of antenatal care. Effectiveness and satisfaction in antenatal care: Spastics International Medical Publications/William Heinemann Medical Books ...; 1982. p. 1-21.

2. Mathole T, Lindmark G, Majoko F, Ahlberg BM. A qualitative study of women's perspectives of antenatal care in a rural area of Zimbabwe. Midwifery. 2004;20(2):122-32.

3. Tunçalp Ö, Pena-Rosas JP, Lawrie T, Bucagu M, Oladapo OT, Portela A, et al. WHO recommendations on antenatal care for a positive pregnancy experience-going beyond survival. BJOG: An International Journal of Obstetrics \& Gynaecology. 2017;124(6):860-2.
4. Smolina K, Hanley GE, Mintzes B, Oberlander TF, Morgan S. Trends and determinants of prescription drug use during pregnancy and postpartum in British Columbia, 2002-2011: a population-based cohort study. PloS one. 2015;10(5):e0128312.

5. Simkhada B, Porter MA, Van Teijlingen ER. The role of mothers-in-law in antenatal care decisionmaking in Nepal: a qualitative study. BMC pregnancy and childbirth. 2010;10(1):1-10.

6. Oyinlola O, Sunmola A, Opayemi A, Mayungbo O. Barriers to antenatal care use, child birth experience and level of education on actual attendance among pregnant women. International Journal of Psychology and Educational Studies. 2018;5(3):72-80.

7. Gazmararian JA, Schwarz KS, Amacker LB, Powell CL. Barriers to prenatal care among Medicaid managed care enrollees: patient and provider perceptions. HMO practice. 1997;11(1):18-24.

8. Strickland J, Strickland DL. Barriers to preventive health services for minority households in the rural south. The Journal of Rural Health. 1996;12(3):206-17.

9. Målqvist $\mathrm{M}$, Lincetto $\mathrm{O}, \mathrm{Du} \mathrm{NH}$, Burgess $\mathrm{C}$, Hoa DTP. Maternal health care utilization in Viet Nam: increasing ethnic inequity. Bulletin of the World Health Organization. 2013;91:254-61.

10. Tewodros B, Dibaba Y. Factors affecting antenatal care utilization in Yem special woreda, southwestern Ethiopia. Ethiopian Journal of Health Sciences. 2009;19(1).

11. Agus Y, Horiuchi S. Factors influencing the use of antenatal care in rural West Sumatra, Indonesia. BMC pregnancy and childbirth. 2012;12(1):1-8.

12. Regenstein M, Cummings L, Huang J. Barriers to prenatal care: Findings from a survey of lowincome and uninsured women who deliver at 
Medico-legal Update, January-March 2022, Vol.22, No. 179

safety net hospitals: National Public Health and

Hospital Institute; 2005.
13. Maslow AH. A theory of human motivation.

Psychological review. 1943;50(4):370. 